\title{
濒危植物太白红杉种群年龄结构及其 时间序列预测分析
}

\author{
张文辉 ${ }^{1}$ 王延平 $^{2}$ 康永祥 ${ }^{2}$ 刘祥君 ${ }^{1}$ \\ 1 ( 天津师范大学，天津 300074) 2 (西北农林科技大学，陕西杨凌 712100)
}

摘要 : 为了阐明太白红杉 (Larix potaninii var. chinensis) 种群的年龄结构和未来发展趋势, 合理保护现有资源, 在太 白山地区调查了 29 个样地 $(10 \mathrm{~m} \times 10 \mathrm{~m})$ 对处于不同生境的 5 个种群的年龄结构、静态生命表和时间序列预测进 行了分析。种群年龄结构分析表明, 各种群个体数量主要集中于 III、IV、V、VI、VI龄级(个体数量比重占 $68.64 \%$ ), 幼、老龄个体数量较少。受所处生境条件影响, 不同种群年龄结构特点不同 海拔较低的种群 (B) 由于水热条件适 宜 林内有林窗出现 幼龄级个体数相对丰富; 而其他种群由于幼龄个体严重缺乏, 衰退趋势明显。太白红杉不同 种群生命表和存活曲线的分析表明，尽管所处的生境差异较大, 但存活曲线基本属于 Deevey III型 种群偏离典型存 活曲线的程度与幼苗缺乏程度有关，一般 V - IX 龄级死亡率较高。时间序列分析表明, 在未来 20、60、100 和 200 年中, 各太白红杉种群均会呈现老龄级株数先增加后减少的趋势, 种群稳定性维持困难。太白红杉种群年龄结构 和动态趋势与银杉 (Cathaya argyrophylla) 等其他濒危植物比较, 导致种群衰退的原因相似:在郁闭的林下种子萌芽 和幼苗生长困难。应该利用太白红杉喜光、耐旱和中老年个体产种量丰富的特性，对现有太白红杉林分实行就地 保护，合理抚育管理。低海拔地区，应适当间伐非目的树种; 在高海拔地区应间伐浓密的灌木层; 适度清理或扰动 草本地被物层, 使太白红杉种子能够顺利落入土壤, 顺利萌芽、定居, 形成不同龄级的种群更新体系。

关键词 : 生命表, 存活曲线, 种群数量动态, 时间序列

中图分类号 : Q948 文献标识码 : A 文章编号 : 1005-0094(2004)03-0361-09

\section{Age structure and time sequence prediction of populations of an endan- gered plant , Larix potaninii var. chinensis}

\author{
ZHANG Wen-Hui ${ }^{1}$,WANG Yan-Ping ${ }^{2}$, KANG Yong-Xiang ${ }^{2}$, LIU Xiang-Jun ${ }^{1}$ \\ 1 Tianjin Normal University, Tianjin 300074 \\ 2 Northwest Sci-Tech University of Agriculture \& Forestry, Yangling , Shaanxi 712100
}

\begin{abstract}
The Taibai larch ,Larix potaninii var. chinensis, is an endangered plant only found in the Qinling Mountains in China. It is densely distributed on Mount Taibai and plays an important role in environmental protection in the high altitude zone. In order to characterize the age structure and dynamics of the L. potaninii var. chinensis population so as to better conserve its resources, 29 plots $(10 \mathrm{~m} \times 10 \mathrm{~m})$ were investigated on Mount Taibai. The analysis of the age structure of five populations of L. potaninii var. chinensis showed that most individuals (68.6\%) were concentrated in the $60-140$ year age classes. Younger and older individuals were dramatically few. Because of different environmental conditions , different populations developed their own characteristic age structure. The population in L. potaninii var. chinensis - Abies fargesii - Lonicera hylocomium - moss association showed a stable development tendency. However, another four populations in L. potaninii var. chinensis - A. fargesii-Betula utilis var. sinensis - Rhododendron clementinae association , L. potaninii var. chinensis - Rhododendron clementinae - Lonicera hylocomium - moss association , L. potaninii var. chinensis - Rhododendron capitatum - Juniperus pingii var. wilsonii - Carex sp. association and $L$. potaninii var. chinensis - Rhododendron purdomii $-R$. capitatum association all showed obvious declining tendencies. The analysis of life tables and survival curves showed that even under different environmental conditions, survival curves of $L$. potaninii
\end{abstract}


var. chinensis populations belonged to Deevey type III , and death peaks of different populations were the in period of 100 - 180 years old. Time sequence prediction models for different populations after 20 ,60, 100,200 years indicated that the numbers of old individuals would increase in the beginning and finally decrease, giving rise to difficulties for maintenance of these populations. The age structure and dynamic trends of L. potaninii var. chinensis populations were similar to those of other endangered species in China , such as Cathaya argyrophylla. The key cause for population decline was that shade in the forest obstructed germination and seedling growth. In situ conservation should be strengthened in future , especially for middle and old individuals with reproductive ability. The heliophytic and xerophytic characteristics of $L$. potaninii var. chinensis should be considered and special counter-measures for fostering the species should be made according to these biological characteristics and habitats. In the lower altitudes, non-target species in the tree layer and some shrub species should be thinned. In higher altitude areas , actions for fostering forest, such as cutting shrubs , clearing herbs , etc. should be taken , so as to create the environmental condition for development of young seedlings of $L$. potaninii var. chinensis.

Key words : life table , survival curve , population dynamics , time sequence ,Larix potaninii var. chinensis

植物种群数量动态是植物个体生存能力与外界 环境相互作用的结果 (Crawley , 1986)。研究不同 生境条件下植物种群年龄结构和生命表以及存活曲 线不仅可以反映种群现实状况, 还可以展现植物种 群与环境抗争的关系, 尤其对于濒危植物的保护和 利用研究具有重要意义( Manuel \& Molles ,2002; 张 文辉 ,1998)。

太白红杉 (Larix potaninii var. chinensis) 是落叶 松属红杉组红杉分布最东界的一个变种, 属国家二 级保护植物（狄维忠和于兆英，1987），现仅分布于 我国秦岭地区海拔 $2800-3500 \mathrm{~m}$ 的高山、亚高山地 区，也是森林线地区唯一可成纯林的树种。但由于 海拔高、气候寒冷、生长季节短、土壤瘦薄等因素, 个 体生长不良，偏冠、枯梢现象普遍，种群更新不良，大 部分地段的种群呈衰退趋势。研究太白红杉种群数 量动态特征不仅对种群保护, 而且对于维持秦岭高 山地区生态平衡具有重要的现实意义。

20 世纪 80 年代以前, 对太白红杉的研究主要 集中在分类、分布以及群落特征和林学特性方面 (李家俊,1989)。90 年代以来,陈存根和彭鸿 (1994) 从持续利用的角度对其群落结构、分类、演 替和生物量进行了较为系统的研究; 阎桂琴 (2001)、间桂琴等 (2001) 和赵桂仿 (2001) 对其群落 特征及物种多样性进行了研究。但有关太白红杉种 群年龄结构及数量动态预测的研究还未见报道。本 文通过对太白红杉不同生境种群年龄结构、生命表、 存活曲线及种群数量的时间序列预测分析, 目的是 阐明其种群年龄结构及未来发展趋势, 为合理保护
利用资源提供依据。

\section{1 研究区概况}

太白红杉以太白山地区分布最为集中，在接近 森林线和山梁地区形成大面积连片分布 (李家骏, 1989 )。本次研究的取样范围在 $33^{\circ} 49^{\prime}-34^{\circ} 08^{\prime} \mathrm{N}$, $107^{\circ} 41^{\prime}-107^{\circ} 52^{\prime} \mathrm{E}$, 海拔 $2900-3500 \mathrm{~m}$ 。研究区内 年平均降雨量 $500-956 \mathrm{~mm}$, 年均温 $5.9-7.5^{\circ} \mathrm{C}$, 土壤类型主要为暗棕壤, $\mathrm{pH}$ 值为 6.0-6.8 主要植 被类型为牛皮桦 (Betula utilis var. sinensis)、巴山冷 杉(Abies fargesii) 及太白红杉等组成的高山针叶林 或针阔混交林。太白红杉林上部为森林分布上限, 下部常与巴山冷杉或牛皮桦等树种混交, 主要灌木 为太白杜鹃 (Rhododendron clementinae)、头花杜鹃 $(R$. capitatum) 等( 雷明德, 1990)。根据陈存根和 彭鸿 (1994) 对太白红杉群落的分类研究和本次实 地调查,太白山地区的太白红杉林可以划分成 5 种 群丛。本研究将每一群丛中太白红杉所有个体作为 一个种群 ,5个群丛中所有太白红杉个体为本地区 太白红杉种群(总和) ( Moore \& Chapman ,1986)。5 个种群分别是 :太白红杉 - 巴山冷杉 - 牛皮桦 - 金 背杜鹃群丛 (Association Larix potaninii var. chinensis - Abies fargesii - Betula utilis var. sinensis - Rhododendron clementinae) 中的种群 A、太白红杉 - 巴山冷 杉 - 忍冬 - 苔藓群丛 (Association Larix potaninii var. chinensis - Abies fargesii - Lonicera hylocomium moss) 中的种群 B、太白红杉 - 金背杜鹃 - 忍冬 - 苔 藓群丛 (Association Larix potaninii var. chinensis - 
Rhododendron clementinae - Lonicera hylocomium moss ) 中的种群 C、太白红杉 - 头花杜鹃 - 爬柏 - 苔 草群丛 (Asssociation Larix potaninii var. chinensis Rhododendron capitatum - Juniperus pingii var. wilsonii - Carex sp. )中的种群 D、太白红杉 - 太白杜鹃 头花杜鹃群丛 (Association Larix potaninii var. chinensis - Rhododendron purdomii - R. capitatum) 中 的种群 E、本地区太白红杉群系 (Larix potaninii var. chinensis family) 中的种群总和 $\mathrm{F}$ 。不同种群的生境 概况见表 1 。

\section{2 研究方法}

\section{1 样地调查}

经充分踏查后, 考虑不同群落类型和生境条件 的代表性, 在不同典型群落中共布设 $10 \mathrm{~m} \times 10 \mathrm{~m}$ 的 样地 29 块(表 1)，每块样地内设 $5 \mathrm{~m} \times 5 \mathrm{~m}$ 灌木样 方 3 个 , 1 $\mathrm{m} \times 1 \mathrm{~m}$ 草本样方 3 个。调查内容:(1) 生 境:包括地形地貌、人为干扰强度、土壤、气象、坡向、 坡位, 内容见表 1 ; (2) 群落学特征:包括群落组成、
高度、盖度等，方法见董鸣等(1996)；(3) 乔木树种 定位: 以样地一边为 $\mathrm{X}$ 轴, 其垂直边作为 $\mathrm{Y}$ 轴建立 平面直角坐标系, 记录每一株太白红杉和乔木种的 坐标值、胸径 (幼苗测基径)、树高和冠幅；(4) 太白 红杉树龄确定 胸径大于 $3 \mathrm{~cm}$,用胸径确定年龄;胸 径小于 $3 \mathrm{~cm}$ 利用其基径确定。依据西北农林科技 大学林学院森林经理资料室太白红杉解析木资料, 绘制胸径生长过程图（图 1)，分别拟合曲线，得到胸 径与年龄的关系方程 :

$$
\begin{aligned}
& Y=-21.23377+34.89765 \times \lambda^{0.0588 D} \\
& R=0.99975, \chi^{2}=0.43254(\text { alt. }<3200 \mathrm{~m})(1) \\
& Y=-\frac{1}{0.03396} \times \ln \left(\frac{30.59714-D}{135.48754 D}\right) \\
& R=0.998485, \chi^{2}=0.27579(\text { alt. }>3200 \mathrm{~m})
\end{aligned}
$$

式中, $Y$ 为个体年龄, $D$ 为胸高直径。所调查样地中 个体的年龄按其海拔区间分别选用以上两式确定。

\section{2 年龄结构图绘制}

\begin{tabular}{|c|c|c|c|c|c|}
\hline $\begin{array}{c}\text { 环境因子 } \\
\text { Environmental factors }\end{array}$ & $\begin{array}{c}\text { 种群 A } \\
\text { Population A }\end{array}$ & $\begin{array}{c}\text { 种群 B } \\
\text { Population B }\end{array}$ & $\begin{array}{c}\text { 种群 C } \\
\text { Population C }\end{array}$ & $\begin{array}{c}\text { 种群 D } \\
\text { Population D }\end{array}$ & $\begin{array}{c}\text { 种群 E } \\
\text { Population E }\end{array}$ \\
\hline 1. 海拔 Altitude (m) & 2950 & 3050 & 3222 & 3227 & 3400 \\
\hline 3. 坡度 Gradient $\left({ }^{\circ}\right)$ & 37 & 25 & 25 & 31 & 35 \\
\hline 4. 坡位 Slope position & $\begin{array}{c}\text { 中 } \\
\text { Middle }\end{array}$ & $\begin{array}{c}\text { 上 } \\
\text { Upper }\end{array}$ & $\begin{array}{c}\text { 中上 } \\
\text { Middle - upper }\end{array}$ & $\begin{array}{c}\text { 上 } \\
\text { Upper }\end{array}$ & $\begin{array}{c}\text { 上 } \\
\text { Upper }\end{array}$ \\
\hline 5. 乔木层盖度 Coverage of tree layer (\%) & 70 & 70 & 60 & 60 & 50 \\
\hline 6. 土壤厚度 Soil thickness ( cm) & 77 & 55 & 45 & 37 & 28 \\
\hline 7. 土壤 $\mathrm{pH}$ 值 Soil pH & 6.7 & 6.5 & 6.2 & 6.5 & 6.2 \\
\hline \multicolumn{2}{|c|}{ 8. 土壤有机质含量 Content of soil organic matter $(0-10 \mathrm{~cm})(\%) 5.5$} & 5.7 & 6.7 & 7.8 & 4.1 \\
\hline 9. 土壤水分含量 Water content of soil $(0-10 \mathrm{~cm})(\%)$ & 46 & 47 & 50 & 44 & 42 \\
\hline 13. 种群平均密度 Mean density (ind. $/ 100 \mathrm{~m}^{2}$ ) & 4.00 & 4.38 & 5.75 & 11.50 & 23.30 \\
\hline 14. 人为干扰强度 Intensity of human disturbance $(0-1)$ & 0.3 & 0.4 & 0.2 & 0.3 & 0.5 \\
\hline 15. 样地数量 No. of plots & 6 & 6 & 6 & 6 & 5 \\
\hline
\end{tabular}

以 20 年为一个龄级 统计每一样地内各龄级的

表 1 太白红杉不同种群所在群丛中的环境因子

Table 1 The environmental factors in the association where Larix potaninii var. chinensis population lived

表中 $1-9,13$,为样地调查的平均值。其中土壤取样是地表 $0-10 \mathrm{~cm}$ 混合样品, 所有样地一天内完成 $; \mathrm{pH}$ 值在室内应用 ZD-2 型电位滴定计测 定, 有机质含量应用重铬酸钾法测定; 圷壤含水率应用烘干法测定。10-11 为 2000 和 2001 年 7 月利用干湿球温度计 (DMH2) 观测的平均值 (每 $5 \mathrm{~d}$ 观测 1 次 观测时刻 $700,1000,1300,1500,18$ D0 ) 。12 的基本数据参照雷明德 (1990)。14 是人为干扰, 强度最大设为 1 , 最小为 0 ,不同群丛中干扰强度值根据调查结果予以赋值。

$1-9,13$, Mean values of plot investigations , of which , soil samples $(0-10 \mathrm{~cm})$ in all plots were taken on one day , $\mathrm{pH}$ of soil was measured by Meter of Electric Voltage (ZD-2) , the content of soil organic matter by method of Heavy Chrome Acid and the water content by baking method. 10 - 11 , Mean values measured by Dry-Wet Meter of Temperature( DMH2) during July in 2000 and 2001 , once every 5 days, at 7 00,10 00, 13 00, 15 00 and 18 , 00, respectively. 12, From Lei (1990). 14 , The maximum values were given 1 when the human disturbance was severe , and the minimum value were given 0 when the human disturbance was not found in the stand according to plot investigation. 


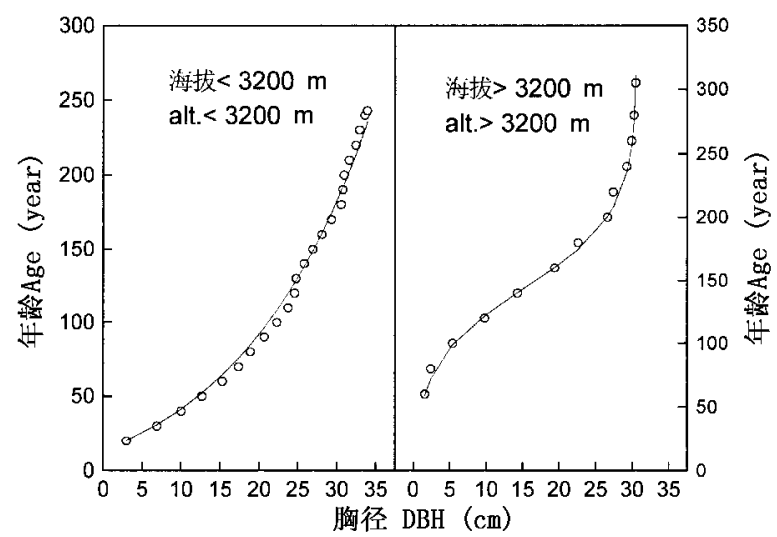

图 1 不同海拔区间太白红杉年龄与胸径的关系

Fig. 1 Relationship between age and DBH (diameter at breast height) of Larix potaninii var. chinensis at different altitudes

株数 将同群丛内所有样地不同龄级的株数合并 组 成各种群的年龄结构基本数据。以龄级为横坐标， 以株数 $/ 100 \mathrm{~m}^{2}$ 为纵坐标绘制年龄结构图 (Crawley, 1986 )。

\section{3 种群静态生命表和存活曲线}

以各种群年龄结构数据为基础编制静态生命 表，具体方法见文献( Manuel \& Molles ,2002; 江洪， 1992 )。

2.4 种群数量动态的时间序列预测模型

$$
M_{t}^{(1)}=M_{t-1}^{(1)}+\frac{X_{t}-X(t-n)}{n}
$$

式中 $M_{t}^{(1)}$ 是近期 $n$ 个观测值在 $t$ 时刻的平均值，称 为第 $n$ 周期的移动平均。本文以 $n$ 值为各龄级株 数; $t$ 分别取 20 年、60 年、100 年和 200 年,对末来 种群发展趋势进行预测，具体原理和方法见文献 ( 谢衷洁, 1990 ;张文辉,1998)。

\section{3 结果与分析}

\section{1 不同太白红杉种群年龄结构}

图 2 A-E 为分布于海拔 $2900-3500 \mathrm{~m}$ 的高海 拔区间的 5 个太白红杉典型群丛内各种群的年龄结 构图。其中图 2-A 是太白红杉 - 巴山冷杉 - 牛皮桦 - 金背杜鹃群丛中太白红杉种群的年龄结构。该群 丛乔木层以太白红杉为主, 伴有巴山冷杉和牛皮桦， 灌木层以金背杜鹃占优势。从图中可以看出太白红 杉种群在 I、II 龄级和 VII、VIII龄级分别出现断代现 象, IV 龄级个体数最多达 2.25 株 $/ 100 \mathrm{~m}^{2}$,VI龄级时 仅剩 0.25 株 $/ 100 \mathrm{~m}^{2}$ 。该群落乔木层郁闭度大, 林
下太白红杉幼苗难以存活, 种群的衰退现象比较明 显。

图 2-B 为太白红杉 - 巴山冷杉 - 忍冬 - 苔藓群 丛中太白红杉种群年龄结构。该群丛中乔木层巴山 冷杉占有一定比例, 但巴山冷杉处于其分布上限, 个 体死亡导致林窗出现，太白红杉幼苗幼树较多，I、 II 、III IV 龄级个体数比例合计为 $63.16 \%$ 。从图中 来看, 各龄级太白红杉密度相对较小, 但各龄级株数 波动不大。该群落下的太白红杉种群具有一定的发 展潜力。

图 2-C 示太白红杉 - 金背杜鹃 - 忍冬 - 苔藓群 丛中太白红杉种群年龄结构。该群丛广泛分布于阴 坡和半阴坡 现存面积较大。乔木层为太白红杉, 灌 木层金背杜鹃茂密 林下的草本物种类稀少, 腐殖质 厚达 $15 \mathrm{~cm}$ 。在某些阴湿地段, 有大量藓类。灌木 层的密集致使林下太白红杉幼苗难以更新，I 龄级 个体很少, 密度只有 0.125 株 $/ 100 \mathrm{~m}^{2}$ 。

图 2-D 是太白红杉 - 头花杜鹃 - 爬柏 - 苔草群 丛中太白红杉种群年龄结构图。该群丛多见于半阴 坡半阳坡。乔木层几乎全为太白红杉占据,优势灌 木为头花杜鹃。草本层发达, 主要由苔草 (Carex lanceolata)、野青茅(Deyeuxia scabrescens) 等构成。 太白红杉密度和各龄级株数波动很大, 其中 IV 龄级 植株最多, 密度可达 3 株 $/ 100 \mathrm{~m}^{2}$ 。该群落内太白红 杉个体生长良好, 平均高 $9.6 \mathrm{~m}$, 平均胸径 $19.5 \mathrm{~cm}$, 林分总体郁闭度较大, 太白红杉幼苗库相对不足。

图 2-E 是太白红杉 - 太白杜鹃 - 头花杜鹃群 丛、太白红杉种群年龄结构图。该群丛多分布于高 海拔的梁顶地区，乔木层生长不良，郁闭度低，生产 力低下。灌木层几乎由太白杜鹃、头花杜鹃占据, 铺 地而生, 郁闭度大。草本层发育不良。从图中可以 看出太白红杉种群以 V、VI、VII、VIII龄级为优势龄级, 个体数比重达 $79.17 \%$ 。而 I 、II 龄级幼苗、幼树严 重缺乏 种群呈现衰退趋势。

图 2-F 是太白红杉种群 (总和) 年龄结构图。 上述 5 个群丛在太白山高海拔地区基本为连片分 布 将不同群丛的个体统计可以得到太白山地区太 白红杉种群 (总和) 年龄结构图。总体看, 本地区太 白红杉种群幼龄级株数少, 中龄级株数较多。III 、 $\mathrm{IV} 、 \mathrm{~V} 、 \mathrm{VI} 、 \mathrm{VII}$ 龄级为太白红杉种群的优势龄级，个体 数量比重占 $68.64 \%$ 。可以预见 100 年后, 目前处 于中龄级范围的太白红杉个体将全部进级到老龄期 


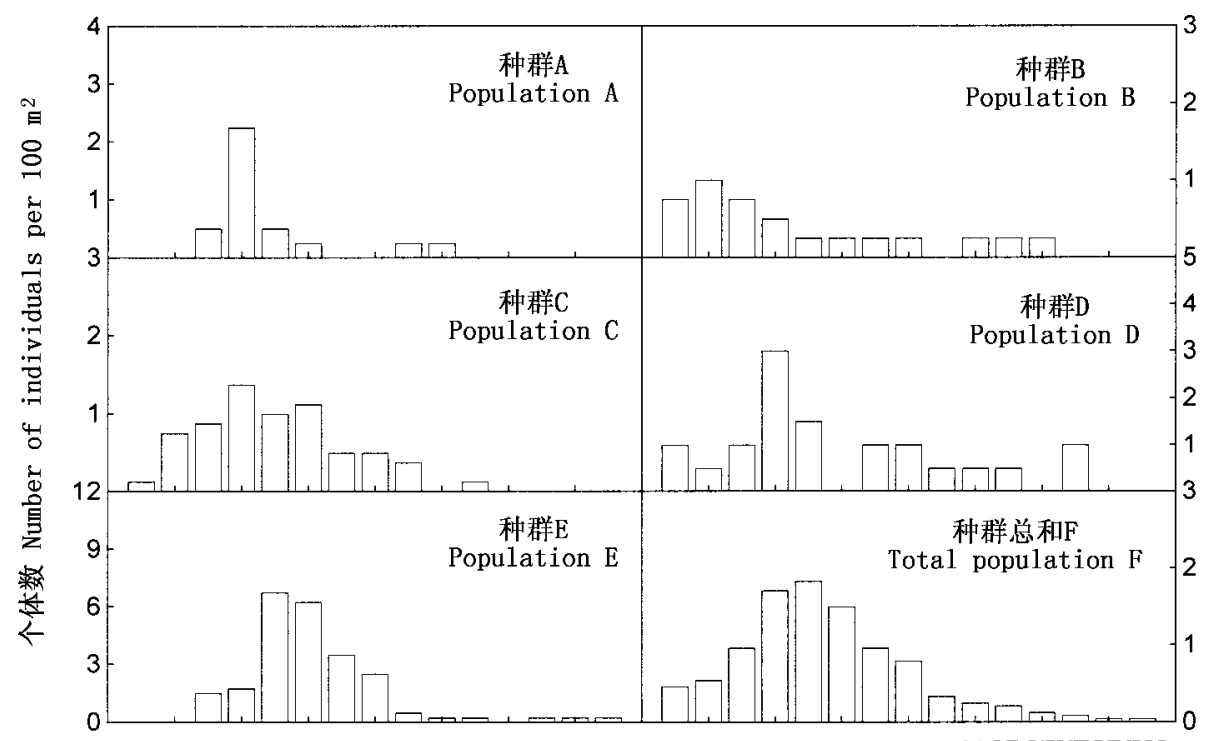

I II III IV V VI VII VIII IXX XI XIIXIIXVXV I II III IV V VIVII VII IX X XI XIIXII XVXV

龄级 Age class

图 2 太白红杉不同种群年龄结构

Fig. 2 The age structure of different Larix potaninii var. chinensis populations

表 2 太白山太白红杉种群标准生命表

Table 2 The standard life table of Larix potaninii var. chinensis population in Mt. Taibai

\begin{tabular}{|c|c|c|c|c|c|c|c|c|}
\hline $\begin{array}{c}\text { 龄级 } \\
\text { Age stage }(x)\end{array}$ & $\begin{array}{c}\text { 标准化存活量 } \\
l_{x} \\
\end{array}$ & $\begin{array}{c}\text { 死亡量 } \\
d_{x}\end{array}$ & $\begin{array}{c}\text { 死亡率 } \\
q_{x}\end{array}$ & $\begin{array}{c}\text { 区间寿命 } \\
L_{x}\end{array}$ & $\begin{array}{c}\text { 总寿命 } \\
T_{x}\end{array}$ & $\begin{array}{c}\text { 期望寿命 } \\
e_{x} \\
\end{array}$ & $\begin{array}{c}\text { 存活数 } \\
a_{x}\end{array}$ & $\begin{array}{c}\text { 消失率 } \\
K_{x}\end{array}$ \\
\hline I & 208 & -107.3 & -516 & 261.4 & 5284 & 25.4 & 9.1 & -0.4 \\
\hline III & 518 & -312.8 & -604 & 674.7 & 4606 & 8.9 & 22.7 & -0.5 \\
\hline IV & 831 & -168.9 & -203 & 915.5 & 3932 & 4.7 & 36.4 & -0.2 \\
\hline V & 1000 & 248.9 & 249 & 875.6 & 3016 & 3.0 & 43.8 & 0.3 \\
\hline VII & 598 & 141.6 & 237 & 527.4 & 1466 & 2.5 & 26.2 & 0.3 \\
\hline VIII & 457 & 191.8 & 420 & 360.7 & 938 & 2.1 & 20.0 & 0.5 \\
\hline IX & 265 & 114.2 & 431 & 207.8 & 578 & 2.2 & 11.6 & 0.6 \\
\hline $\mathrm{X}$ & 151 & 32.0 & 212 & 134.7 & 370 & 2.5 & 6.6 & 0.2 \\
\hline XI & 119 & 36.5 & 308 & 100.5 & 235 & 2.0 & 5.2 & 0.4 \\
\hline$X V$ & 16 & 16.0 & 1000 & 8.0 & 8 & 0.5 & 0.7 & 2.8 \\
\hline
\end{tabular}

$l_{x}$, Standard living number $; d_{x}$, Number of dying during interval $; q_{x}$, Average mortality rate per age stage $; L_{x}$, Life between the interval $; T_{x}$, Total life ; $e_{x}$, Mean expectation of life $; a_{x}$, Alive number $; K_{x}$, Killing power during interval

后, 如果没有幼龄个体对中龄株数的补充，必然影响 太白红杉种群的整体稳定性。

\section{2 太白红杉种群静态生命表及存活曲线分析}

\subsection{1 太白红杉种群标准生命表分析}

Wretten (1980) 曾指出“: 从很多森林得到的生 命表有可能综合为标准生命表,用于与其他森林作
比较”。江洪 (1992) 在研究川西地区 (Picea asperata) 云杉种群生命表时认为, 云杉各林型的生命表表 现的是不同生境条件下的种群数量动态, 是以标准 生命表为基础的变形,而标准生命表反映的是种群 基本属性。表 2 为 29 个调查样地按 20 年为 1 龄级 编制的太白红杉种群标准生命表。从表 2 中可以看 
出该种群最大编表年龄为 298 年生。太白红杉 I、 II 、III IV 龄级死亡率为负, 说明幼苗库严重不足, 该 种群要保证持续发展至少需要补充相应数量的幼 苗, 否则种群将走向衰退。在 V、VI、VII、VIII IX 龄级， 累积死亡量达 $86.34 \%$,而以后各龄级的累积死亡量 仅为 $11.36 \%$ 。这一方面说明该种群的维持依赖于 中龄个体, 另一方面也说明种群进入中龄期后, 个体 对营养空间的需求不断增大, 基于对光照、水分、养 分和空间生态位竞争 种群自疏和他疏作用增强, 导 致了较高的死亡量。IX龄级的个体已进入太白红杉 的中龄后期 环境条件能较好地满足生长需求, 死亡 率减少。在进入生理衰老期后 种群死亡率不高。

\subsection{2 太白红杉各种群存活曲线分析}

以太白红杉种群生命表中标准化存活量 $l_{x}$ 为 纵坐标，以龄级为横坐标分别绘制了太白红杉不同 种群 (图 3A-E) 及种群 (总和) (图 3-F) 存活曲线。 如果以标准化最高存活量为起点,太白红杉的存活 曲线基本属于 Deevey III 型。从图中可以发现太白 红杉多数个体都能达到 80 年生 (IV 龄级)，大于 100 年生后 (V 龄级) 死亡率较高, 200 年生以后死 亡率减缓。比较不同太白红杉种群的存活曲线可以
看出 种群 B 更接近典型 Deevey III 型存活曲线,而 种群 $\mathrm{A} 、 \mathrm{C} 、 \mathrm{D} 、 \mathrm{E}$ 偏离较大, 基本呈 偏正态”。图中 也直观地反映了种群数量动态的某些特征:(1) 在 不同生境中太白红杉种群数量动态特征为 幼、老龄 株数少,, $\mathrm{V}-\mathrm{X}$ 龄级死亡率最高。(2) 5 个太白红杉 种群由于环境条件的差异, 种群死亡率高峰期出现 分化，不同种群各年龄阶段的死亡率有差异。(3) 不同生境中太白红杉种群衰退原因不同 种群 $\mathrm{A} 、 \mathrm{C}$ 个体受巴山冷杉、牛皮桦、金背杜鹃等上层乔灌木的 庇荫 幼苗、幼树难以发展; 种群 D 密度大, 个体间 竞争激烈，林下光照不足，幼龄苗木少，种群 $\mathrm{E}$ 所处 环境经常出现极端气候而导致个体偏冠、枯梢，甚至 死亡, 但林下灌木郁闭, 导致幼苗更新不良, 种群 B , 由于林窗出现, 为林下幼苗生长创造了条件, 相对而 言幼龄株数较多, 是具有扩展潜力的唯一种群。

3.3 太白红杉种群数量动态的时间序列预测分析 以太白红杉各种群及种群总和各龄级株数为原 始数据, 按照一次平均推移法计算出各龄级在未来 20 年、60 年、100 年及 200 年后的株数, 将结果绘成 年龄与株数关系图 (图 4)。从图 4 中可以看出, 太 白红杉 A、C、D、E种群各龄级株数峰值在预测序列

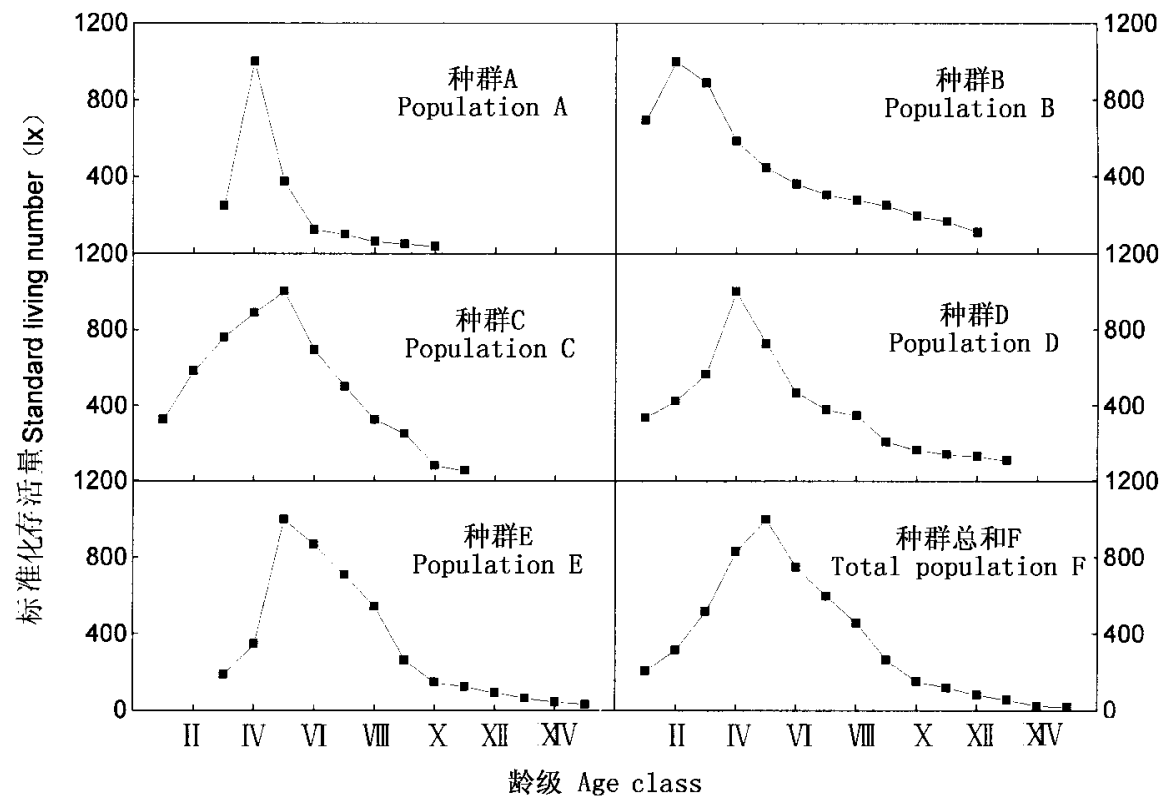

图 3 太白红杉不同种群存活曲线

Fig. 3 Survival curves of different Larix potaninii var. chinensis populations 


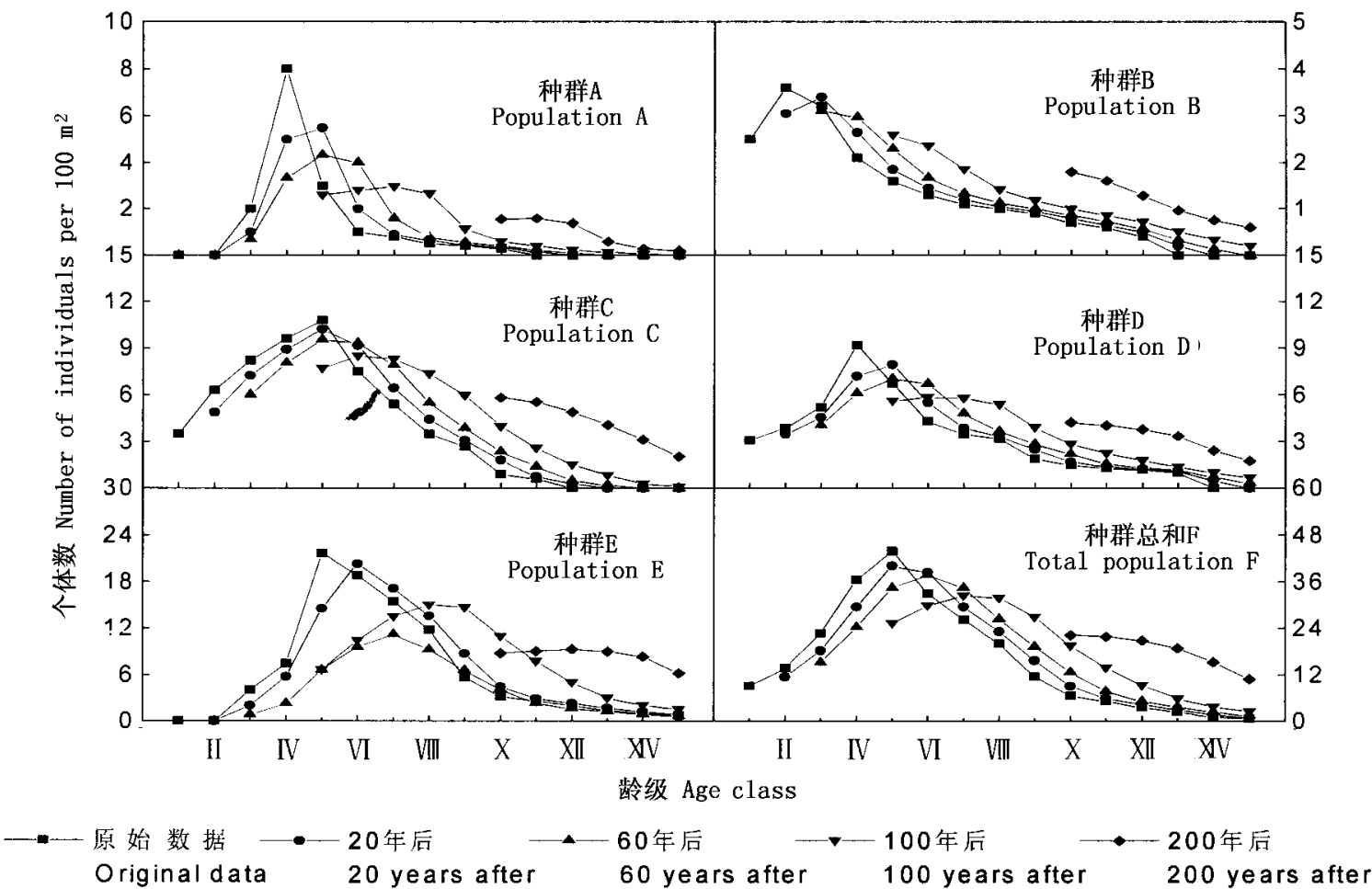

图 4 太白红杉各种群数量动态时间序列预测

Fig. 4 Time sequence prediction of quantitative dynamics of different Larix potaninii var. chinensis populations

中依次向后推移。随时间推移，老龄个体逐渐增多， 幼龄株数更显不足, 最终老龄株数也急剧减少, 呈衰 退势态。可以推断，如不采取适当的抚育管理措施， 为幼苗更新创造条件，太白红杉种群的稳定性很难 维持。在种群 B 内 , I、II 龄级的个体基本能补充 III IV 龄级由于种群个体发育迁出或死亡造成的缺 失,使种群能持续稳定发展。

4 讨论

\section{1 种群基本特征}

本地区太白红杉种群年龄结构、生命表和种群 数量预测分析表明 种群幼龄级个体数较少 ,中老龄 个体数量较大，随着时间的推移，种群将更趋于老 化。不同种群由于所处立地条件不同，年龄结构呈 现各自的特点。处于海拔较低的种群 B 由于林窗 出现, 水热条件适宜 幼龄级个体数相对丰富。而其 他种群由于幼苗、幼树的严重缺乏，甚至出现连续的 断代现象，使太白红杉种群总体上呈衰退趋势。不 同太白红杉种群存活曲线的分析表明，尽管不同种 群所处的生境差异较大, 但如果以标准化后最高存 活量为起点,存活曲线基本属于 Deevey III 型, 即种
群个体早期死亡率较高，进入生理衰退年龄之后，死 亡率比较稳定。不同种群偏离典型存活曲线的程度 与幼苗缺乏程度有关。由时间序列预测可知，在未 来 20、60、100 和 200 年后, 不同太白红杉种群均会 呈现老龄级株数先增加后减少的趋势，如幼龄植株 缺少的现状不能改善, 种群维持困难。

太白红杉种群的数量动态特征与银杉 (Cathaya argyrophylla)、鹅掌楸 (Liriodendron chinense) 等其他 濒危植物的年龄结构和生命表非常相似 (谢宗强 等,1999 贺善安和郝日明,1999) 都属于喜光、长寿 命、多次结实的木本植物 (张文辉等,2002)。这类 植物一般在环境条件改善后容易恢复 (Manuel \& Molles ,2002 ; Silvertown \& Charlesworth ,2003)。但 太白红杉分布范围仅限于秦岭高海拔地区, 并且低 海拔 (1000 $\mathrm{m}$ 以下)地区造林不容易成活，对生境要 求特殊, 这就增加了保护的紧迫性和特殊性, 应该引 起相关部门的高度重视。

\section{2 种群稳定性}

一般植物年龄结构和静态生命表以及对种群动 态预测都是基于现有调查数据, 能够反映种群的基 本属性(Ludwig \& Reynolds , 1990 ; Crawley ,1986)。 
但是 种群数量特征是种群生物学特性与多种环境 因素共同作用的结果 (Manuel \& Molles , 2002)，只 要环境条件改善, 目前的不利状态有可能改变。太 白红杉喜光、耐旱，出现目前这种衰退特征的原因主 要是上层乔灌木层郁闭度过大，不能形成幼苗所致。 一旦环境因素变化, 如林窗出现, 林下地被物被扰 动, 灌木层和乔木层被间伐, 都可能为太白红杉种子 萌发、幼苗定居创造条件。据调查 ,5个种群平均球 果产量为 1843 个 $/ 100 \mathrm{~m}^{2}$ 饱满种子量为 183200 粒 $/ 100 \mathrm{~m}^{2}$,野外人工播种的种子发芽率为 $42.7 \%$ 。 这表明本地区太白红杉种群具有产生大量幼苗的潜 力。种群更新的主要问题可能是在天然条件下种子 向幼苗转化过程遇到障碍 5个群丛中 1-10 年生 幼苗量仅为 0.96 株 $/ 100 \mathrm{~m}^{2}$, 天然条件下种子转化 成幼苗的概率非常低, 仅为 0.00001229 。很明显, 如果维持目前生存状态，林下太白红杉幼苗不能正 常更新 种群可能就会走向衰退。这与其他濒危植 物，如裂叶沙参 (Adenophora lobophylla)、银杉、我鸟掌 楸等比较相似, 天然条件下种子转换成幼苗的概率 过低是种群濒危的主要原因( 谢宗强等,1999;张文 辉等 2002)。因此，维持种群稳定性的关键是要为 种子萌芽、幼苗定居和生长创造适宜的条件。种群 $\mathrm{B}$ 幼苗数量较多的主要原因可能是林窗的出现。目 前太白红杉种群中老年个体仍保持着比较旺盛生殖 能力, 应该充分利用这一特征, 采取适度干扰地被 物、开林窗等措施, 促进天然更新。

\section{3 未来经营措施}

只要进行合理经营管理, 太白红杉种群可以保 持其相对稳定性。从森林经营学角度看, 太白红杉 种群大部分个体已经进入 $\mathrm{V}$ 龄级以上的成年阶段， 可以间伐。但是，太白红杉为秦岭特有种，基因资源 特殊而珍贵, 并且处于森林分布上线地区, 在科学研 究和环境保护上意义重大，应该尽量保护现有资源。 如果盲目间伐也可能导致成年个体减少, 产种量下 降 种群恢复更加困难。最稳妥的办法是采用 就 地保护 抑制非目的树种、促进种群更新”的经营策 略,促进林分向异龄林方向发展。在具体抚育管理 措施上，应该针对不同群丛类型和生境条件，采用不 同抚育管理措施: 低海拔地区, 应适当间伐乔木层非 目的树种(如巴山冷杉和牛皮桦)，以及过度密集的 灌木树种 (如金背杜鹃); 在高海拔地区, 主要是间 伐浓密的灌木层 (如头花杜鹃、太白杜鹃)，对过分
浓密草本活地被物层也要进行适度清理或扰动, 使 太白红杉种子能够顺利落入土壤，创造种子萌芽、幼 苗定居和发展条件，形成不同龄级的种群更新体系。

\section{参考文献}

Chen, C. G. (陈存根) and Peng, H. (彭鸿) . 1994. The phytocoenological features and classification of the forests of Larix chinensis in Qinling range. Acta Scientia Sinicae (林业 科学), 30:487 - 496. (in Chinese with English abstract)

Crawley, M. J. 1986. Plant Ecology. Blackwell Scientific Publications, London, $97-185$.

Di, W. Z. (狄维忠) and Yu, Z. Y. (于兆英). 1987. The First Set of the Chinese Rare and Endangered Plants in Shaanxi Province (陕西省第一批国家珍稀濒危保护植 物). Northwest University Press, Xi'an, $72-75$. (in Chinese)

Dong, M. (董鸣), Wang, Y. F. (王义凤) and Kong, F. Z. (孔繁志). 1996. Standard Methods for Observation and Analysis in Chinese Ecosystem Research Network - Survey, Observation and Analysis of Terrestrial Biocommunities (中 国生态系统研究网络观测与分析标准方法——陆地生 物群落调查观测与分析). Standards Press of China, Beijing, $20-81$. (in Chinese)

He, S. A. (贺善安) and Hao, R. M. (郝日明). 1999. Study on the natural population dynamics and the endangering habitat of Liriodendron chinense in China. Acta Phytoecologica Sinica (植物生态学报), 23: 87 - 95. (in Chinese with English abstract)

Jiang, H. (江洪) . 1992. Study on Population Ecology of Picea asperata (云杉种群生态学研究). China Forestry Publishing House, Beijing, 33 -78. (in Chinese)

Lei，M. D. (雷明德). 1990. Vegetation of Shaanxi (陕西植 被). Science Press, Beijing, 45-130. (in Chinese)

Li, J. J. (李家骏). 1989. The Collection Papers of Synthetic Exploration of Natural Reserve in Taibai Mountain (太白山 自然保护区综合考察论文集). Shaanxi Normal University Press, $\mathrm{Xi}^{\prime}$ an, $3-21$. (in Chinese)

Ludwig, J. and Reynolds, J. (Translated by Li, Y. Z. (李育 中), Wang, W. (王炜) and Pei, H. (裴浩)). 1990. Statistical Ecology (统计生态学). Inner Mongolia University Press, Huhhot, 6-25. (in Chinese)

Manuel, C. and Molles, J. 2002. Ecology, Concept and Applications (2nd edn.). McGraw-Hill Companies, New York, $186-254$

Moore, P. D. and Chapman, S. B. 1986. Methods in Plant Ecology (2nd edn.). Blackwell Scientific Publications, London, $377-437$.

Silvertown, J. and Charlesworth, D. (Translated by Li, B. ( 李 
博) and Lu, J. Z. (陆建忠)). 2003. Introduction to Plant Population Biology (4th edn.) (简明植物种群生物学). China Higher Education Press, Beijing, 74 -77. (in Chinese)

Wretten, S. D. 1980. Field and Laboratory Exercise in Ecology. Edward Arnod, New York, 66-105.

Xie, Z. J. (谢衷洁). 1990. Time Sequence Analysis (时间序 列分析). Beijing University Press, Beijing, 88 -145. (in Chinese)

Xie, Z. Q. (谢宗强), Chen，W. L. (陈伟烈) and Lu，P. (路 鹏). 1999. Population statistics and age structure of endangered plant Cathaya argyrophylla. Acta Ecologica Sinica (生态学报), 19: 523 - 528. (in Chinese with English abstract)

Yan, G. Q. (阎桂琴).2001. Study on the community and population ecology of Larix chinensis in Qinling range. Chinese
Journal of Applied Ecology (应用生态学报), 12: 824 828. (in Chinese with English abstract)

Yan, G. Q. (阎桂琴), Zhao, G. F. (赵桂仿) and Hu, Z. H. (胡正海). 2001. The study on Larix chinensis community characteristics and species diversity in Mts. Qinling. Acta Botanica Boreali-Occidentalia Sinica (西北植物学报), 21: 497 -506. (in Chinese with English abstract)

Zhang, W. H. (张文辉), Zu, Y. G. (祖元刚) and Liu, G. B. (刘国彬).2002. Population ecological characters and analysis on endangered cause of ten endangered plant species. Acta Ecologica Sinica (生态学报), 22: 1512 1520. (in Chinese with English abstract)

Zhang, W. H. (张文辉). 1998. Study on Population Ecology on Adenophora lobophylla (裂叶沙参种群生态学研究). Northeast Forestry University Press, Harbin, $7-22$. (in Chinese)

\section{《生物多样性》第三届编委会在京编委第一次会议纪要}

《生物多样性》第三届编委会在京编委第一次会议于 2004 年 4 月 10 日上午 900-1200 在中国科学院动物研究所召开。 主编汪小全, 副主编 (以下按姓氏拼音排序) 蒋志刚、谢宗强、庄文颖 编委高贤明、葛颂、郭良栋、李义明、李振宇、刘杏忠、马克 明、马克平、杨祝良、张德兴 编辑时意专、间文杰、周玉荣 植物所文献信息中心主任崔金钟参加了会议。

会议由汪小全主编主持, 首先由编辑部汇报了近几年的工作情况、刊物所取得的进展以及目前存在的问题。与会编委对 编委会的职责重新认识,围绕多项议题进行了广泛讨论，主要达成以下共识：

编委会的核心任务是组织稿件、论文学术质量把关和争取、吸引稿源。

- 期刊应办出特色, 要把满足读者的需求放在首位, 即增加可读性并及时反映学科动态。

- 实行责任编委制。编委与编辑部应分别对稿件的学术质量和编辑质量严格把关，对于争议较大的稿件由相关领域的 副主编或主编裁定。

- 重申稿件送审之前必须事先与审者取得联系, 审稿人对稿件的评价需要细化和具体。有争议的稿件录用后要与持不 同意见的审者沟通。

对稿件的退修改应尽量一次完成。退修改信件的格式要按照国际规范 应当包括编辑部意见、责任编委意见和两审意 见(有时可能包括副主编或主编意见)。作者对修改意见的逐条回复也要认真和具体，否则应退回重写。

英文摘要应适当加长, 对于原始研究论文, 要求必须写清楚研究目的、材料、方法、结果和结论, 可考虑采取结构式英文 摘要。

修改征稿简则，有关投稿格式的规定要更具体。关键词、参考文献尤其是图、表格式应进一步规范化, 达到规范的稿件 才能送审。

- 建议每年刊登引用率最高的前 3 篇文章, 评选年度最佳封面, 并给予适当的物质奖励。

- 拓宽稿源 吸引优秀稿件 建立相对稳定的作者群体: (1) 编委就一些热点问题组织专题稿件; (2) 相对薄弱的研究领 域的文章应鼓励和引导; (3) 对综述性文章要严格把关。

总之，《生物多样性》将本着 立足国内、展望国际”的办刊原则，力求国内地位稳步提高 ,国际影响逐步扩大。 